\title{
DESIGN AND PRODUCTION OF TROPHIES FOR SELECTED SPORTS AND GAMES IN KNUST
}

\author{
I. K. Agyei ${ }^{1}$ and J. Adu-Agyem² \\ 'Department of Industrial Art, \\ Faculty of Industrial Art, \\ ${ }^{2}$ Department of General Art Studies \\ Faculty of Fine Art \\ Kwame Nkrumah University of Science and Technology, Kumasi, Ghana
}

\begin{abstract}
Design and production of trophies for games and sports particularly in a form of metal art has been in existence for so many years. Presently they are practiced with much improvement and modern technology as compared to the ancient times where leaves, horns and other objects were used as trophies to award warriors and those who excelled in other sporting disciplines. Trophies are said to be prizes or cups which are given to an individual, a group of people or a nation for performing excellently in any sporting activity such as tennis, football, volley ball, basket ball and horse racing etc. Today, trophies serve so many purposes, such as, a souvenir of remembrance; as a stool for one to look at and strive for excellence in life as well as financial gains. KNUST does not have its own trophies for the Sports and Games they engage in. This publication seeks to display the design and subsequent production of four trophies for Kwame Nkrumah University of Science and Technology (KNUST) to enhance the prestige of its awards and solve some related problems. The technique for production is the lost wax. Metal scraps such as brass and copper were the main materials used for the production. Especially the lost wax technique of production was very efficient and effective in the production of the trophies. Experimental and Descriptive Research methods based on the quantitative and qualitative research approaches were employed. It is recommended that Metalsmiths and other Metal Artists as well as students experiment with other materials and techniques in the production of trophies to bring variety in the field of trophy production.
\end{abstract}

Keywords: Trophies lost wax, metal scraps, sports and game, KNUST.

\section{INTRODUCTION}

Savage (1970) and Agyei (2007) contend that trophies play a very expedient role in sports and games. The need for trophies to induce excellence and competition in games and sporting activities cannot be overemphasized. As far as competitive games and sports in the world are concerned, trophies appear to be inevitable. They add that history proves that excellence, competitive games and sporting activities are induced by presentation of trophies. According to Borger (1989), early Greek memorials of victory took the form of the arms and armor of an enemy displayed on the branches of an oak 
tree and lopped seas to resemble a human figure. These were consecrated within a shrine. Later, trophies such as those set up after the victories over the Persian at Marathon and Salamis consisted of columns or towers on high base or mounds, embellished with sculpture and containing decorative groups of bronze armor. Newman (1994) says in Hellenistic times, the motif of the armor began to appear as a decoration carved on the building itself. Throughout the Roman era, trophies, often on a huge scale, were erected as symbols of conquest and often incorporated a mound over the fallen enemies. Collections of captured arms were made both for public memorials as well as private families (Harold, 1970).

For years, Kwame Nkrumah University of Science and Technology, has engaged in various national and international games and sporting activities for which trophies have been awarded for the Sports and Games it excelled in.

The immediate past Vice-Chancellor of KNUST, the late Prof. Kwesi Andam initiated the inclusion of tennis, swimming and other games and sports as elective courses for undergraduate students to broaden existing academic programmes in particular. In addition, KNUST now offers staff and students opportunities to engage in physical exercises and competitions outlined in VC's initiative. However, in spite of these activities, KNUST does not have its own trophies for sports and games such as soccer, hockey, tennis, swimming, basketball, athletics and lawn tennis, it engages in. KNUST's collection of trophies is bought on the open market, and do not bear the university's logo and hence are not unique or identifiable with the university (Winfred Awadzi, Personal Communication, 2004). For instance, the University of Ghana, Legon and University of Cape Coast cannot boast of their own trophies for sports and games they embark on at their campuses.

The purpose of this project is therefore to identify, describe and assess the types and quality of trophies available for selected sports and games in KNUST and to design and produce sample trophies for KNUST to enhance the prestige of its awards at the University. It also establishes the possibility of employing resources available in the College of Art (KNUST) to design and produce quality trophies for selected sports and games in the University.

\section{MATERIALS AND METHODS \\ Materials and Tools}

Materials used for the production of trophies for Sports and Games in KNUST include wood, sheets of non-ferrous metals such as copper, brass and aluminium, Sulphuric acid, nitric acid and other chemicals like hydrochloric acid were also used. Nitric Acid was used to etch the crest and the inscriptions on the trophies. Charcoal and clay were also put together and used to make moulds for casting the trophies. Equipment used included buffing machine, electroplating machine, drilling machine, polishing machine, milling machine, grinding machine, gas torch, anvil, vice, furnace and stakes. Tools necessary for the production of the trophies included tweezers, some type of pliers such as the round nose, flat nose and ring pliers. Other tools used were shears and cutting pliers, needle files as well as big files, jewelers saw flame and blades, the rule and triangular rule, brass brushes, wooden and metal mallets.

\section{Methodology}

Descriptive and Experimental Research methods based on the qualitative and quantitative research approaches were employed. The Descriptive method of research is necessary because trophies existing at the Sports Section of KNUST had to be documented, described and analysed before coming out with a design that would in the long run solve problems existing ones could not. This method was used to describe the various tools, materials and equipment used in the project. It was also used to describe the design and production processes and the appreciation of the results.

The experimental research method was used to assess the suitability of available tools, materials and equipment used in the project (Best, 1981). Experiments were conducted to find out 


\section{Agyei and Adu-Agyem}

the suitability of the use of either copper or brass for the production of the trophies. Experiments were as well conducted to find the relevant and suitable method of production and the method of lost wax (cire perdue) was finally agreed on. The population for the study of this project involved the Sports men and women in general at KNUST. Since it is practically impossible to reach every member of the target population, the purposive sampling method was employed to select 4 workers of KNUST at the Sports Section and 20 artists with sports interest in the College of Art, KNUST for interviews. These formed the sample population. This method of sampling makes it plausible to randomly select people with similar characteristics from the target population to be studied.

To triangulate data obtained through the interviews, observations were also made (Leedy and Ormrod, 2005).According to Amenuke (1991), observation as a research tool was also necessary because information provided by respondents through interviews could be inadequate, biased or untrue. Observation techniques of data collection make it possible for the researcher to obtain first hand information. The researcher thus visited the Sports Section of KNUST at the Old Laundry, Sports units of all the Halls of KNUST, such as Queens Hall, Independence Hall, Unity Hall and University Hall to observe critically the available trophies there. This specifically was done to test the validity of data gathered through the interviews conducted. Photographs were taken where necessary for authenticity and confirmation. Trophies found and observed critically were assessed, analyzed and criticized to serve as the basis for the design and production of trophies for selected Sports and Games in KNUST.

Sulphuric acid and other chemicals like hydrochloric acid were used to prepare pickle solution to clean the metals and finally gold plating solution was used to plate the finished products. Nitric Acid was used to etch the crest and the inscriptions on the trophies.

Design and Production Stages

To make the trophies easily identified with KNUST, the university crest was carefully studied and incorporated in all the designs for the trophies. The idea development was thus from the crest of the University. The project was started by making preliminary sketches and drawings. The appropriate designs were selected with the help of artists and other sports enthusiasts at the Sports Unit of KNUST for the production of the trophies.

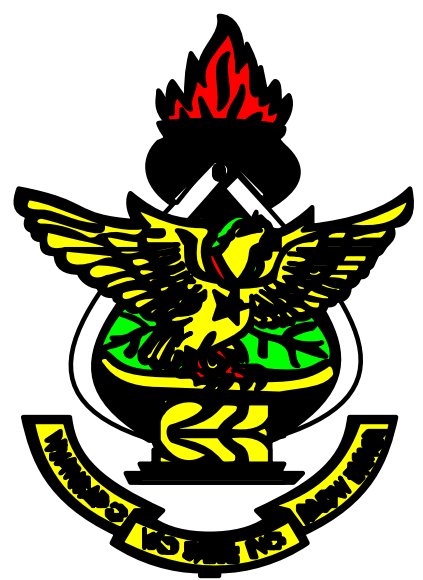

Fig. 1: The Crest of KNUST

This is the crest of KNUST from which all trophy designs were developed (Fig 1). It is composed of an eagle, leaves at the background of the eagle, "Nyansapo stool", a pot with flaming fire, a pair of calipers and the inscription written in "twi language" as "Nyansapo wosanne badwemma," literally meaning, "it takes a wise person to untie the wisdom knot."Samples of the Designs developed and created from the crest have been shown in Figs 2 -7.

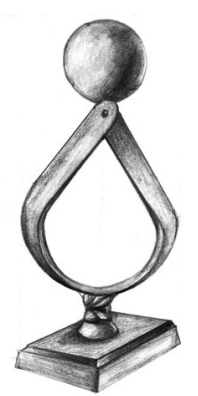

Fig 2 Table Tennis

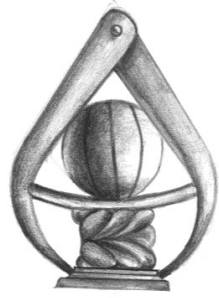

Fig 3. Basketball 


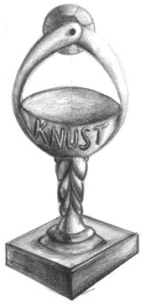

Fig 4. Hockey

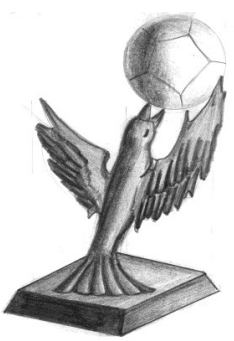

Fig. 6: Lawn Tennis

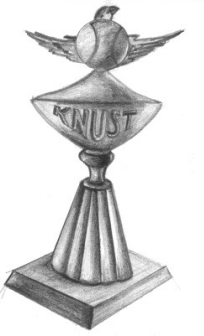

Fig. 5: Volleyball

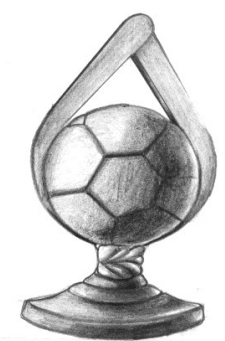

Fig.7: Soccer/Football

Below are the final four designs selected for the production of the trophies. All of them remained the same whiles the one for the volleyball was redesigned.

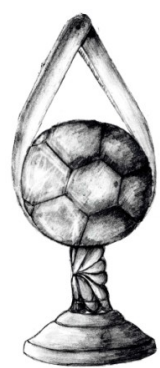

Fig. 8: Soccer

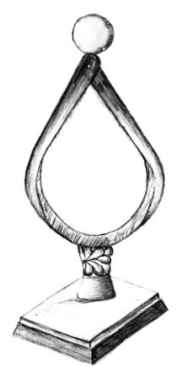

Fig.10: Table Tennis

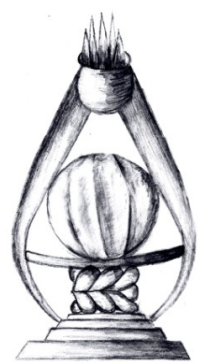

Fig. 9: Basketball

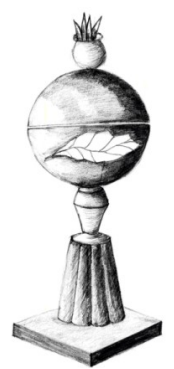

Fig.11: Volleyball
All these designs were finally erected on wooden base as shown in Figs. 17 - 20 .

The production of trophies basically employed the use of lost wax method or technique of casting in combination with the use of some materials, tools and equipment discussed previously. Some parts of the trophies had to be pierced and etched with the use of nitric and hydrochloric acids. Designs of figures $8,9,10$ and 11 were chosen. Lost Wax technique of casting was used to produce all the trophies together with Milling, Etching and Electroplating.

Trophies were modeled into various parts and cast by using the lost wax technique before welding them together.

In the lost wax technique, gates with reservoir and vents were attached to the work to aid the casting processes. Molten metal that would be poured through the gates and vents would also help the air to escape in case some were trapped.

Milling is the process where metal goes through roller to get it round or flat for subsequent working processes.

Etching is the use of acid to corrode some portions of a metal in order to get the required design to stand out on the metal and finally, Electroplating is the process of coating a metal with a different metal in a molten form.

These various parts of each of the trophies were carved into the exact dimensions in a mixture of clay and charcoal. Wax wires were also made.

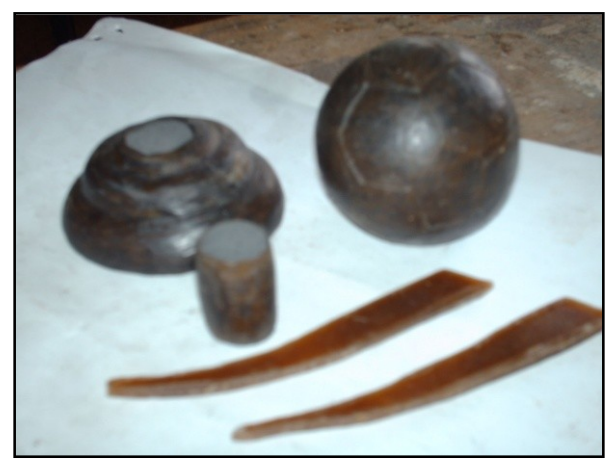

Fig. 12: Components of Soccer Trophy 


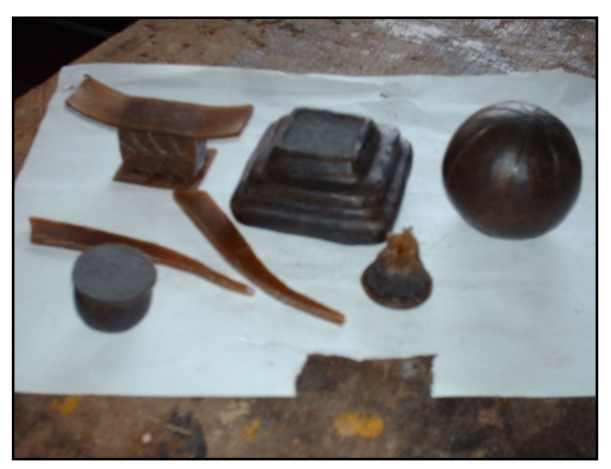

Fig.13: Components of Basketball Trophy

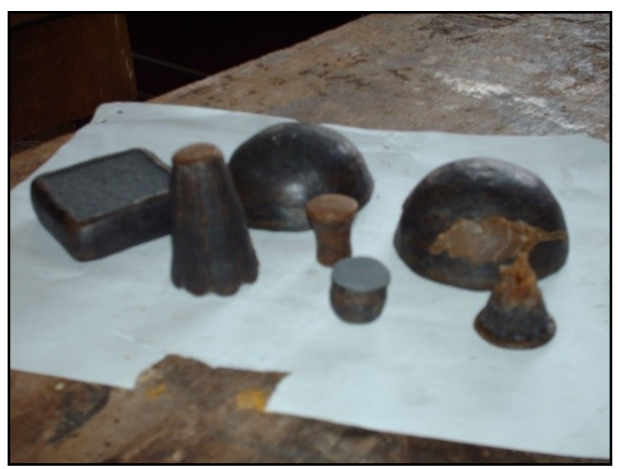

Fig.14: Components of Volleyball Trophy

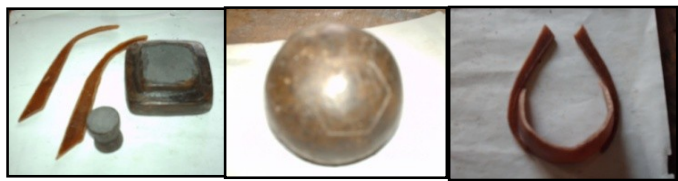

Fig.15: Components of Table Tennis Trophy

These wax wires were carefully coiled around the carved blocks. This was to help get all the cast pieces in hollow form so that it would avoid the works being in solid form which makes them heavy or bulky. The coiled wires were gradually smoothened by using the modeling tools. This was carefully done to get a very smooth surface.

Mixture of charcoal and clay meshed into very fine grains were sprayed and painted on the surface of each part. This was done several times after allowing each mould to dry for a while. The works were dried in the open air but not in the sun since the wax can easily melt when dried in the sun. Subsequent coatings were made until finally rough mixture of clay, charcoal and fiber were used to make the final coating or mould more solid and strong.

The final moulds were allowed to dry for about a week before being used for casting. All the moulds were put into a furnace with the gates turned upside down and heated to a temperature such that all the imbedded wax would melt away leaving the created impression.

Casing of fridge motor full of brass scraps was used as a crucible and put on another furnace for it to burn until it became molten.

All the moulds were heated red -hot and carefully, with the aid of tongs, put into sand packed in a flask with the gates up. The molten brass metal was carefully and gradually poured into all the moulds and allowed to dry for some time. All the moulds were later put into water and broken to expose the cast works. All trapped mixture of clay and charcoal were removed by using the metal modeling tools and brass brush to get all the works as shown in the Fig. 16.

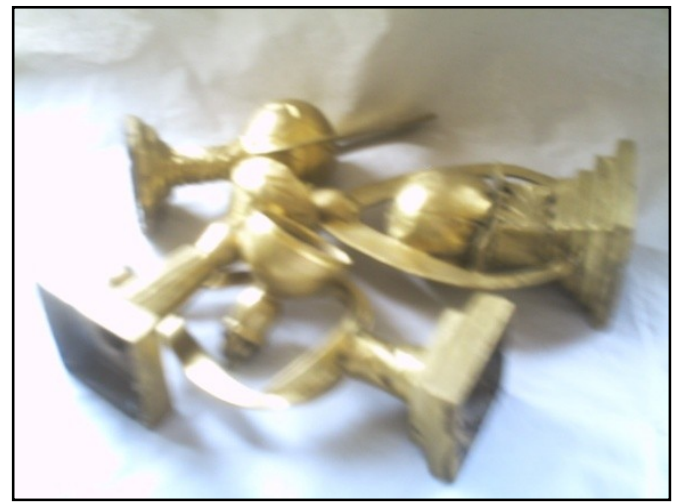

Fig. 16: Cast Works

\section{RESULTS AND DISCUSSION}

The results of this project have been grouped into five categories based on the findings obtained on the use of tools, materials, equipment, techniques and appreciation of the finished works of trophies in Figures 17, 18, 19 and 20. 


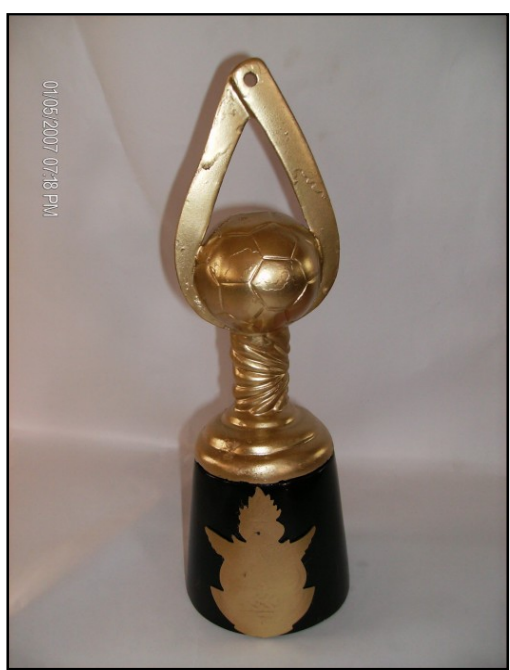

Fig. 17: Final Trophy for Football

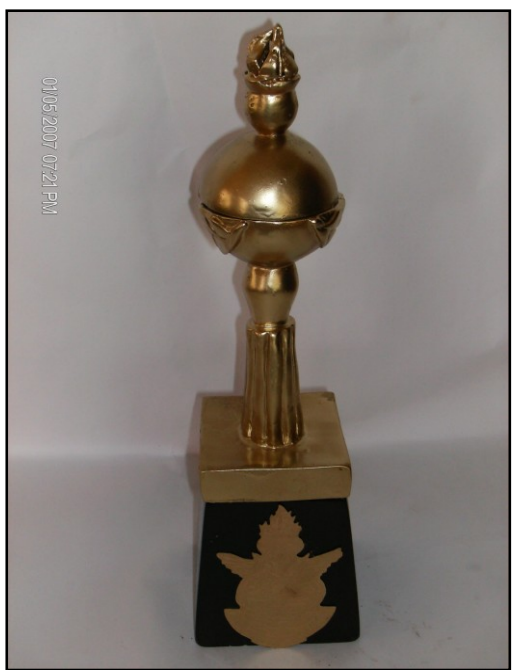

Fig. 19: Final Trophy for Volleyball

\section{Tools}

Wax modeling tools created some problems because they were too big and therefore had to be improvised to be able to smoothen the surfaces. Bamboo and other tools were used to work on the wax surfaces since the final cast works were the exact replica of the wax models.

The use of jewelers saw frame and blade also posed some problems. This was used to remove

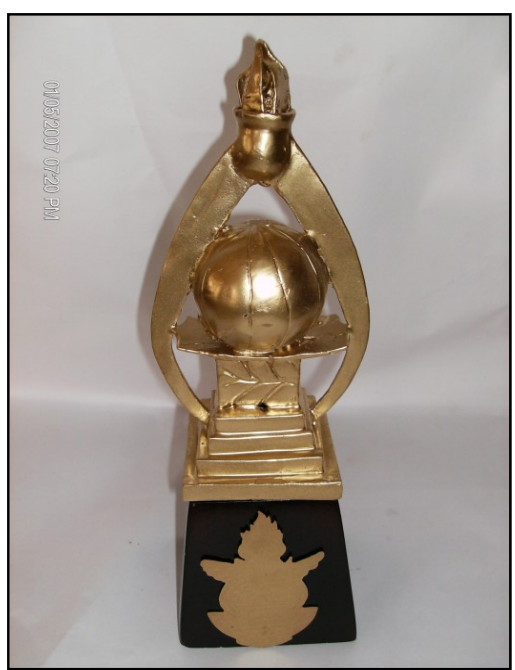

Fig. 18: Final Trophy for Basketball

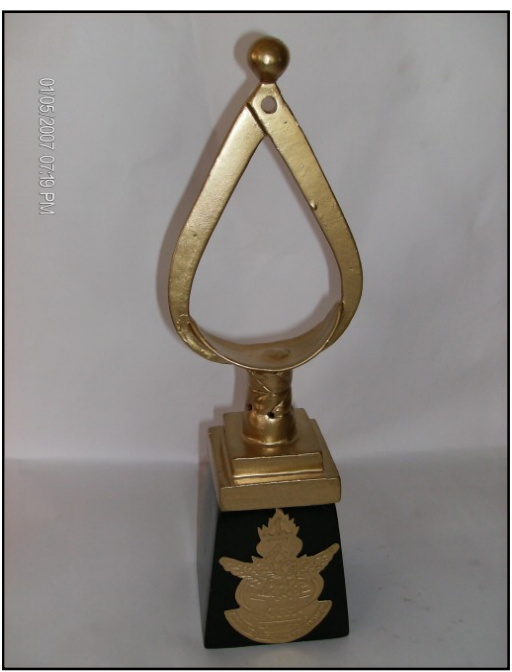

Fig. 20: Final Trophy for Table Tennis

all gates and vents on all the cast pieces. Cast pieces were mostly hard. A lot of blades got broken and had to be replaced so many times causing a lot of waste of jeweler's blade. This problem was solved by using the blade to cut through bee wax to oil the teeth for easy and smooth cutting.

\section{Materials}

It was observed that the use of nitric acid for 
etching the copper sheet was very effective and smooth whiles the use of hydrochloric acid was very corrosive and gave rough etched surface.

\section{Equipment}

The finding supported the fact that it is possible to use the lost wax technique to produce sample trophies. The technique was very delicate and needed a lot of experience since it normally appeared that the cast pieces do not come out well as a result of the wax not melting properly from the mould or the mould not being heated properly.

The designs of these trophies were composed of elements such as lines, shapes and dots which were arranged artistically and aesthetically to achieve design principles such as depth, rhythm, harmony, dominance, variety and unity. Movements were achieved as a result of the curved lines which ran through from the top to the bottom of these designs as indicated in Figures 17, 18, 19 and 20. Converging and diverging lines in the drawing of the trophy also created an illusion of distance. Arrangement of lines of different sizes and length in the design created different shapes giving an impression of solidarity of forms in the designs. The designs therefore have curves, pentagon and octagon shapes and curved triangles as the "nyansapo" depict variety, repetition, rhythm and dominance in the designs. The colour yellow is in harmony with the colour black.

The designs which are meant for Inter- Hall Competitions in KNUST symbolize unity and knowledge. These trophies which have steps leading to the "nyansapo" which symbolize knowledge means the step by step procedure one has to go through to attain knowledge. The training one or a team would have to go through to win matches and for that matter to obtain a trophy is in consonance with the acquisition of knowledge. The "nyasapo" which means taking pains and patience to acquire knowledge would definitely lead to winning the trophy hence the progression from the base to the top of the trophies. The calipers which protrude from the circumference of the ball to emerge at one point shows the unity and the technicalities in the game of football, basketball, tennis and volleyball teams would have to go through before they would be able to win a trophy. Step by step procedure, knowledge of the technicalities in the sporting activity coupled with unity would definitely let a team win a trophy after keen competition.

\section{CONCLUSION}

The results of this project of study have shown the possibilities of using the available resources at the Metal Product Design Section of the Department of Industrial Art and Department of General Art Studies, College of Art and Social Sciences to produce sample trophies for Sports and Games activities in KNUST. It also buttresses the fact that the use of lost wax technique to produce trophies in the round for KNUST was possible. This happens to be user friendly method or technique because the trophies are not solid but hollow and light and therefore can be transported to any place for competitions. The trophies were basically produced to instill enthusiasm in the game and sports of KNUST.

The success of this project would give room for all metal design artists and students, art educators and designers to explore in this area to create a variety of trophies for other institutions. This could foster the development of the senses, something which is essential for teaching and learning processes which involves critical observation and careful manipulation of design elements, principles, tools, materials and equipment. The works provide knowledge in the making of trophies for institutions.

\section{REFERENCES}

Agyei, I. K. (2007). Design and Production of Trophies for Sports and Games in KNUST. M.A Thesis, KNUST: Kumasi.

Amenuke, S. K. (1991). General Knowledge in Art for Senior Secondary Schools. London: Evans Brothers Limited.

Best, J. W. (1981). Research in Education. 
(Fourth Edition). New Jersey, Englewood Cliffs: Prentice Hall Inc.

Borger, L. A. (1989). The Dictionary of Antiques and the Decorative Arts. London: Adams Charles Black Ltd.

Gillian, N. (1981). The Arts and Crafts Movement. London: Studio Vista Publishers.

Harold, N. (1994). An Illustrated Dictionary of Jewellery. London : Thames and Hudeon Ltd.
Leedy, P. and Ormrod J.E. (2005). Practical Research: Planning and Design. $\left(8^{\text {th }}\right.$ Edition) U.S. A: Macmillan Publishing Co. Inc.

Osborne, H. (1970). The Oxford Companion to Art. London : Oxford University Press.

Savage, G. (1970). Dictionary of Antique. London: Barrie and Jenkins Ltd. 